УДК [632.3 +632.952]:66-965.61:661.16

НОВЫЙ ПЕСТИЦИДНЫЙ ПРЕПАРАТ НА ОСНОВЕ КОМПЛЕКСОВ ТЕБУКОНАЗОЛА И ПРОИЗВОДНЫХ ГЛИЦИРРИЗИНА

1'Душкин А.В., ${ }^{1}$ Метелева Е.С., ${ }^{1}$ Хомиченко Н.Н., ${ }^{2}$ Власенко Н.Г., ${ }^{2}$ Теплякова О.И., ${ }^{3}$ Халиков М.С., ${ }^{3}$ Халиков С.С.

${ }^{\prime}$ ФГБУН «Институт химии твердого тела и механохимии СО РАН», Новосибирск, e-mail:dushkin@solid.nsk.su;

${ }^{2}$ Сибирский НИИ земледелия и химизаиии сельского хозяйства СФНЦА РАН, Краснообск, e-mail:vlas_nata@ngs.ru;

${ }_{3}^{3}$ ФББУН «Институт элементоорганических соединений им. А.Н. Несмеянова» РАН, Москва, e-mail: salavatkhalikov@mail.ru

Методами механохимии получены перспективные многокомпонентные композиции препаратов для комплексной защиты растений на основе тебуконазола. Применение в этих процессах глицирризиновой кислоты и ее натриевой соли позволило получить протравители семян на основе тебуконазола с улучшенными физико-химическими, технологическими и биологическими параметрами. Испытания препаратов в лабораторных и полевых условиях показали синергизм биологических свойств, проявляющихся в ускорении роста культурного растения, снижении пораженности корневой системы яровой пшеницы и ярового ячменя обыкновенной корневой гнилью и увеличении их продуктивности при снижении нормы расхода действующих веществ препаратов. Показано, что межмолекулярные комплексы тебуконазола на основе глицирризиновой кислоты и ее натриевой соли обладали высокой биологической активностью при сниженном расходе препарата.

Ключевые слова: тебуконазол, глицирризиновая кислота, мицеллы, фунгицидные композиции

\title{
NEW PESTICIDE PRODUCT BASED ON COMPLEXES OF TEBUCONAZOLE AND GLYCYRRHIZIN DERIVATIVES
}

${ }^{1}$ Dushkin A.V., ${ }^{1}$ Meteleva E.S., ${ }^{1}$ Khomichenko N.N., ${ }^{2}$ Vlasenko N.G., ${ }^{2}$ Teplyakova O.I., ${ }^{3}$ Khalikov M.S., ${ }^{3}$ Khalikov S.S.

${ }^{1}$ Institute of Solid State Chemistry and Mechanochemistry SB RAS, Novosibirsk, e-mail:dushkin@solid.nsk.su;

${ }^{2}$ Siberian Institute of Agriculture and chemicals used in agriculture SFNTSA RAS, Krasnoobsk, e-mail:vlas_nata@ngs.ru;

${ }^{3}$ Institute of Organoelement Compounds Nesmeyanov RAS, Moscow, e-mail: salavatkhalikov@mail.ru

Promising multicomponent compositions of preparations for complex protection of plants based on tebuconazole were obtained using mechanochemical methods. The use of glycirrhizic acid and its sodium salt in this processes allowed obtaining of seed desinfectants based on tebuconazole with improved physicochemical, technological and biological parameters. The preparations tests in laboratory and field conditions have shown the synergism of biological properties, appeared by growth acceleration of the cultivated plant, decrease of the root system infestation of the spring wheat and spring barley by common root rot and productivity increase at lower application rates of preparations active substances. It has been shown that intermolecular complexes of tebuconazole based on glycirrhizic acid and its sodium salt possess high biological activity at lower application rates of preparations.

Keywords: tebuconazole, glycirrhizic acid, micells, fungicidal compositions

Одним из наиболее экологичных способов применения химических препаратов в зерноводстве считается протравливание посевного материала. Это объясняется тем, что фунгицидам необходимо разложиться до кущения растений [1]. Во всех развитых странах мира протравливание относят к законодательно обязательному фитосанитарному мероприятию, направленному против комплекса возбудителей болезней зерновых культур, передающихся семенами и сохраняющихся в почве [5]. Эффективность пестицидных препаратов слагается из природы действующего вещества, правильного вы- бора препаративной формы, сохраняющей полезные свойства действующего вещества. Появление новых химических фунгицидов принципиально не меняет общую ситуацию в защите растений от болезней. Опасные заболевания зачастую носят эпифитотический характер, налицо не только увеличение вредоносности известных, но и появление новых опасных видов фитопатогенов [4]. Поэтому новый подход в создании систем комплексной защиты растений от болезней предполагает использование не только фунгицидов, но и различных биологически активных веществ, обеспечивающих вос- 
становление и активацию природных регуляторных механизмов, повышающих биологическое разнообразие в агробиоценозах и их устойчивость, а также продуктивность сельскохозяйственных культур.

Кроме того, важным фактором, влияющим на эффективность препаративных форм пестицидных препаратов, является способность их действующих веществ проникать в объем обрабатываемых объектов зерен, растений и т.Д., что, очевидно, связано со способностью трансмембранного транспорта. В фармации такая способность обеспечивается так называемыми системами доставки лекарств. В последнее время активно развивается направление создания таких систем доставки на основе супрамолекулярных комплексов и везикулярных структур [8]. Основываясь на наших исследованиях в этой области, мы применили развиваемый нами подход механохимического твердофазного получения таких структур [9], для получения пестицидных препаратов на основе тебуконазола (ТБК). Для этого в качестве «вспомогательных» веществ мы использовали глицирризиновую кислоту (ГК) и ее динатриевую соль $\left(\mathrm{Na}_{2} \Gamma \mathrm{K}\right)$. Производные ГК могут встраиваться в липидные биологические мембраны [10] и, предположительно, являться «носителями» низкомолекулярных биологически активных веществ в трансмембранном переносе. В водных растворах производные ГК образуют везикулы - мицеллы, состоящие из 60-100 молекул, в которые включаются молекулы малорастворимых биологически активных веществ [2]. Такие мицеллы обладают мембранотропными свойствами, позволяющими увеличивать трансмембранный перенос ТБК.

\section{Материалы и методы исследования}

В состав разрабатываемых протравителей входили: Тебуконазол от Shenzhen Sunrising Industry Co., Ltd. КНР, содержание основного вещества $\geq 98,0 \%$. Глицирризиновая кислота от Shaanxi Pioneer Biotech Co., Ltd, KHP, содержание основного вещества $\geq 98,14 \%$. Динатриевая соль глицирризиновой кислоты - $\mathrm{Na}_{2}$ ГК от Shaanxi Pioneer Biotech Co., Ltd, КНР, содержание основного вещества $\geq 91,14 \%$.

Совместную механохимическую обработку ТБК и вспомогательных веществ проводили в условиях, описанных нами ранее [2]. Для получения композиции, субстанции ТБК и вспомогательных веществ в выбранных массовых соотношениях при общем весе образца 20 г загружали в металлический барабан (емкость 0,3 л, загрузка мелющих тел - 15 стальных шаров диаметром 22 мм, скорость вращения 157 об/мин) валковой мельницы ВМ-1. Обработку проводили в течение 12 ч, отбирая пробы через каждые 2 ч. Полученные композиции анализировали на содержание действующего вещества (ТБК), растворимость в воде, а также методами гель-проникающей хроматографии. Оптимальное время механохимической обработки выбиралось по критериям максимальной водорастворимости при условии сохранения содержания ТБК не менее $98 \%$ от начального.

Для определения растворимости, полученные композиции, взятые в количествах, содержащих по 0,33 г ТБК растворяли в 10 мл дистиллированной воды при перемешивании в $\left(+25^{\circ} \mathrm{C}, 180\right.$ об/мин.) в течение 3 ч. Концентрацию ТБК в растворе определяли методом ВЭЖХ на хроматографе Agilent 1200 с колонкой Zorbax Eclipse XDB-C18, 4,6×50 мм; температура колонки $+30^{\circ} \mathrm{C}$; детектор диодно-матричный. В качестве элюента применяли систему ацетонитрил - вода (1:1), скорость потока - 1 мл/мин, объем пробы - 5 мкл, детектирование на длине волны 238 нм. Концентрации ТБК определяли относительно его специально приготовленного раствора в этаноле.

Для определения содержания ТБК полученные композиции растворялись в этаноле. Затем полученные растворы анализировались методом ВЭЖХ в вышеуказанных условиях. Молекулярную массу мицелл ГК определяли методом гель-проникающей хроматографии по методике [2].

Определение проникновения тебуконазола во внутренний объем зерна. Зерно пшеницы (сорт Омская 36) обрабатывалось $5 \mathrm{~cm}^{3}$ водной суспензии композиций, а также тебуконазола исходя из количества 0,03 г действующего вещества (ТБК) на 100 г зерна. Смешение суспензии с зерном производили в течение 1 ч в барабане валковой мельницы ВМ-1, однако без загрузки мелющих тел. Обработанное зерно проращивалось в течение 3 дней на увлажненной фильтровальной бумаге при $+25^{\circ} \mathrm{C}$. Затем зерно вместе с ростками высушивали до постоянной массы в вакуумном шкафу при $+60^{\circ} \mathrm{C}$, производили смыв ТБК, не проникшего в объем зерна и оставшегося на его поверхности несколькими порциями этанола до исчезновения пика ТБК в хроматограммах ВЭЖХ. После этого зерно сушилось в течение 24 ч в вакуумном шкафу при $+60^{\circ} \mathrm{C}$ и измельчалось в мельнице ударного типа (кофемолке). Далее, к навеске полученного порошка добавлялось известное количество этанола, смесь перемешивали в течение 20 мин и фильтровали через бумажный фильтр. Концентрацию ТБК в полученном растворе определяли методом ВЭЖХ и производили расчет массы ТБК, содержащегося в 100 г зерна.

Биологические испытания. Для оценки эффективности действия протравителей были проведены лабораторные и полевой эксперименты. Биоиспытания вели на пшенице сорта Омская 36 и яровом ячмене Ача. Уровень оздоровления посевного материала композициями определяли методом рулонов по ГОСТ 12044-93. Опыт включал следующие варианты:

1) контроль (без обработки фунгицидом);

2) перед посевом семена обработаны тебуконазолом (ТБК), в норме 0,3 кг/т;

3) семена обработаны глицирризиновой кислотой (ГК), в норме 0,25 кг/т;

4) семена обработаны натриевой солью глицирризиновой кислоты $\left(\mathrm{Na}_{2} \Gamma\right.$ К $)$, в норме 0,25 кг/т;

5) семена обработаны композицией ТБК $/ \mathrm{Na}_{2}$ ГК $1 / 5$, в норме 0,3 кг/т (ТБК/ $\mathrm{Na}_{2}$ ГК 0,3$)$;

6) семена обработаны композицией ТБК $/ \mathrm{Na}_{2} \Gamma К$ $1 / 5$, в норме 0,1 кг/т (ТБК/ $\mathrm{Na}_{2}$ ГК 0,1$)$;

7) семена обработаны композицией ТБК/ГК 1//5, в норме 0,3 кг/т (ТБК/ГК 0,3$)$; 
8) семена обработаны композицией ТБК/ГК 1/5, в норме 0,1 кг/т (ТБК/ГК 0,1).

Обработку препаратами проводили за 24 ч до закладки опыта. Растворы готовили из расчета расхода воды, применяемого в производственных условиях (10 л/т). В качестве химического эталона использовали фунгицид-протравитель фирмы Bayer Раксил, КС (д.в. тебуконазол) с нормой расхода 0,5 л/т семян.

Полевые опыты закладывали по схеме:

1) контроль (семена не обрабатывали фунгицидом);

2) эталон (перед посевом семена обработаны препаратом Раксил, в норме 0,5 л/т);

3 ) перед посевом семена обработаны композици-

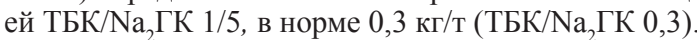

4) перед посевом семена обработаны композицией ТБК/ $\mathrm{Na}_{2} \Gamma К-1: 5$, в норме 0,1 кг/т (ТБК/ $\left.\mathrm{Na}_{2} Г К ~ 0,1\right)$.

Опыт размещался первой культурой после пара. Норма высева 6 млн всхожих зерен /га. Повторность опыта - четырехкратная. Площадь делянки $=23 \mathrm{M}^{2}$, размещение - систематическое. Протравливание проводилось с увлажнением - 10 л/т семян. Уборка урожая - прямым комбайнированием. Урожайность приводилась к стандартной влажности и чистоте согласно ГОСТ 1386.5-93 и 1386-2-81. Учет густоты стояния, продуктивной кустистости растений, отбор снопов для анализа структуры продуктивности проводили непосредственно перед уборкой культур [6]. Развитие и распространенность обыкновенной корневой гнили [7], наличие росторегулирующих эффектов в фазы 3 и 5 листьев.

\section{Результаты исследования и их обсуждение}

Для исследования структуры водных растворов композиций применяли метод гель-фильтрационной хроматографии по вышеописанной методике. Во всех случаях в хроматограммах водных растворов композиций ТБК с ГК, $\mathrm{Na}_{2}$ ГК наблюдались пики высокомолекулярных образований массой 60-100 кДа. Пиков низкомолекулярных соединений (ТБК) не обнаруживалось, что наряду с данными об увеличении растворимости ТБК, см. табл. 1, свидетельствовало о включении молекул ТБК в мицеллы. В исследованном массовом диапазоне соотношений ТБК/вспомогательные вещества от $1 / 1$ до $1 / 10$, наилучшие результаты по стабильности ТБК в процессе получения композиций, а также по увеличению растворимости были получены для композиций $1 / 5$. Именно эти композиции были использованы для дальнейших биологических исследований. Мы также определили проникновение ТБК во внутренний объем зерна по методике, описанной в экспериментальной части. Данные приведены в табл. 1.

Таким образом, полученные результаты подтверждают наше предположение об увеличении проникновения ТБК во внутренний объем зерна при его обработке композициями с ГК и $\mathrm{Na}$ ГК.
Изучение эффективности тебуконазолсодержащих композиций на естественно инфицированном семенном материале показало, что они достаточно активны против возбудителей обыкновенной корневой гнили яровой мягкой пшеницы. И в первую очередь - против основного возбудителя Bipolaris sorokiniana Shoem., обеспечивая $100 \%$-ную эффективность. Рост грибов Fusarium spp. вокруг зерновок пшеницы полностью ингибировал ТБК/Na $Г$ ГК 0,3 и ТБК/ ГК в обеих нормах расхода, ТБК/ $\mathrm{Na}_{2} \Gamma \mathrm{K}$ 0,1 - на $70 \%$. На зерновках ячменя ТБК $/ \Gamma К$ 0,1 и ТБК/ГК 0,3 рост фузариев не подавляли. Alternaria spp. успешнее контролировал комплекс ТБК/ $\mathrm{Na}$ ГК 0,1 (биологическая эффективность $=71,1 \%$; и обе нормы ТБК/ГК (71,8 и 74,4\%). Всхожесть семян пшеницы в рулонах была максимальной $(94,8 \%$; эталон $=68,9 \%)$ при обработке семян ТБК ${ }_{2}$ ГК 0,3 . ТБКNa ГК 0,1

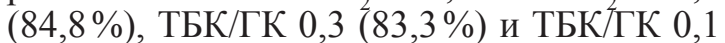
$(90,6 \%)$ всхожесть повышали слабее.

В полевых условиях было показано, что в фазе трех листьев высота растений пшеницы при применении ТБК/ $\mathrm{Na}_{2}$ ГК 0,3 и ТБК/ $\mathrm{Na}_{2}$ ГК 0,1 (24,6 и 26,2 см) достоверно превышала чистый контроль $(23,0$ см) и Раксил $(21,7$ см, НСР05 = 0,18). В фазе пяти листьев достоверные различия отмечены в варианте ТБК/Na ГК 0,1 (38,9 см) с контролем $=37,9$ см $($ НСР05 $=0,28)$, а также ТБК/

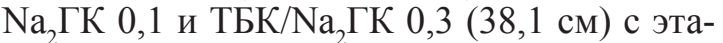
лоном (35,8 см). Высота контрольных растений ячменя (21,8 см), а также обработанных Раксилом (21,2 см) относительно вариантов с применением композиций $(22,5$ и 23,5 cм, НСР05 = 0,21) была достоверно ниже как в фазе трех, так и пяти листьев (в контроле 34,2 см; в эталонном варианте 32,2 см, в вариантах с ТБК/ $\mathrm{Na}_{2} \Gamma \mathrm{K} 38,2$ и 37,3 см, $\mathrm{HCP} 05=0,50)$. На ранних этапах развития повышенная выносливость к почвенно-семенной инфекции у яровой пшеницы и ячменя наблюдалась во всех вариантах опыта (табл. 2).

Эффективность протравливания семян пшеницы при обработке ТБК/ $\mathrm{Na}_{2}$ ГК в норме 0,3 кг/т составила 83,2 и 73,9\% соответственно по развитию и распространенности болезни и превышала эталон, где соответствующие показатели были на уровне 76,6 и $67,9 \%$. С уменьшением нормы расхода ТБК/ $\mathrm{Na}_{2}$ ГК эффективность протравливания снижалась. К фазе трубкования фитосанитарный эффект в варианте ТБК/ $\mathrm{Na}_{2}$ ГК с нормой расхода 0,3 кг/т ослабевал в 2,7 раза, но по-прежнему лучше контролиро- 
вал развитие обыкновенной корневой гнили в посевах пшеницы. Биологическая эффективность ТБК/ $\mathrm{Na}_{2}$ ГК в фазе трех листьев ячменя в обеих нормах расхода $(49,6$ и $51,1 \%)$ превышала таковую эталона (37,9\%). Действие протравливания прослеживалось и в период кущение-трубкование. Более высокий фунгицидный эффект на ячмене наблюдался при применении более высокой нормы расхода.

Протравливание семенного материала оказало влияние на плотность посевов зерновых. К фазе восковой спелости пшеницы достоверно большая (на 14,2\%) густота стояния растений отмечена в варианте с протравливанием ТБК/ $\mathrm{Na}_{2}$ ГК 0,1 , но продуктивный стеблестой увеличивался на $30 \%$ при применении обеих норм расхода ТБК/Na ГК. При посеве семян ячменя, обработанных композициями, оба показателя плотности посева достоверно возрастали: число растений/м² - на 13,4-19,6\% (в варианте с Раксилом - на 10,6\%); продуктивных стеблей - на 27,8-45,5\% (в варианте с Раксилом - на $30 \%$ ). К фазе молочной спелости зерна растения, выросшие из обработанных ТБК/ $\mathrm{Na}_{2}$ ГК семян, оказались более (на 10,3-11,0\% - пшеница; на 13,0-15,6\% ячмень) высокорослые, сильнее (в 1,1-1,3 раза) кустились, чем в контроле. У растений пшеницы и ячменя достоверно увеличива- лась длина колоса во всех вариантах, где высевались семена, протравленные ТБК/ $\mathrm{Na}_{2}$ ГК (табл. 4). Повышенное число колосков в главном колосе у обеих культур получено при посеве семян, обработанных ТБК/ $\mathrm{Na}_{2} Г К ~ 0,3$. Обе нормы расхода ТБК/ $\mathrm{Na}_{2} \Gamma К$ способствовали достоверному увеличению числа зерен в главном колосе пшеницы и ячменя. Масса зерна с одного растения пшеницы повышалась при протравливании семян обеими нормами расхода ТБК/ $\mathrm{Na}_{2} Г К$, ячменя - в варианте ТБК/ $\mathrm{Na}_{2} \Gamma \mathrm{K}$ 0,3, увеличивалась масса 1000 зерен на 1,1 и 1,2 г (пшеница) и 1,5 и 1,2 г (ячмень). Обе нормы расхода ТБК/ $\mathrm{Na}_{2} \Gamma К$ повышали крупность зерновок ячменя относительно эталона на 1,2 и 0,9 г. Сбор зерна пшеницы и ячменя в опытных вариантах достоверно превысил контроль на 0,2 и 0,14 т/га (ТБК/NaГК 0,3 и ТБК $/ \mathrm{Na}_{2}$ ГК 0,1) и 0,19 и 0,14 т/га, применение Раксила увеличило показатель на 0,16 и 0,07 т/га. На ячмене при протравливании семян ТБК/ $\mathrm{Na}_{2} \Gamma К$ урожайность увеличилась на 0,19 и 0,14 т/га (Раксил - на 0,07 т/га).

Обе нормы расхода ТБК/Na $Г$ ГК повышали массу 1000 зерен на 1,1 и 1,2 г (пшеница) и 1,5 и 1,2 г (ячмень). Сбор зерна пшеницы и ячменя в опытных вариантах достоверно превысил чистый контроль на 0,2 и 0,14 т/га; 0,19 и 0,14 т/га.

Данные увеличения растворимости ТБК, а также его содержания

Таблица 1 во внутреннем объеме зерна из композиций с ГК и $\mathrm{Na}_{2} \Gamma К$

\begin{tabular}{|c|c|c|c|c|c|}
\hline $\begin{array}{c}\text { № } \\
\text { П/П }\end{array}$ & $\begin{array}{c}\text { Состав компо- } \\
\text { зиции, массовые } \\
\text { соотношения }\end{array}$ & $\begin{array}{c}\text { Содержание ТБК в \% } \\
\text { от теоретического }\end{array}$ & $\begin{array}{c}\text { Раствори- } \\
\text { мость ТБК, Г/л }\end{array}$ & $\begin{array}{c}\text { Увеличение } \\
\text { растворимости }\end{array}$ & $\begin{array}{c}\text { Содержание ТБК } \\
\text { в мг на 100 г } \\
\text { обработанного зерна }\end{array}$ \\
\hline 1 & ТБК субстанция & - & 0,0341 & - & 4,5 \\
\hline 2 & $\begin{array}{c}\text { Композиция } \\
\text { ТБК/Na ГК } 1 / 5\end{array}$ & 99,0 & 0,2047 & 6 & 10,0 \\
\hline 3 & $\begin{array}{c}\text { Композиция } \\
\text { ТБК/ГК } 1 / 5\end{array}$ & 100,0 & 1,02 & 33,9 & 11,5 \\
\hline
\end{tabular}

Таблица 2

Развитие обыкновенной корневой гнили в посевах мягкой яровой пшеницы и ярового ячменя при обработке семян ТБК/ $\mathrm{Na}_{2} \Gamma \mathrm{K}, \%$

\begin{tabular}{|c|c|c|c|c|c|c|c|c|}
\hline \multirow[t]{3}{*}{ Вариант } & \multicolumn{4}{|c|}{ Пшеница мягкая яровая } & \multicolumn{4}{|c|}{ Ячмень яровой } \\
\hline & \multicolumn{2}{|c|}{3 листа } & \multicolumn{2}{|c|}{5 листьев } & \multicolumn{2}{|c|}{3 листа } & \multicolumn{2}{|c|}{5 листьев } \\
\hline & 1 & 2 & 1 & 2 & 1 & 2 & 1 & 2 \\
\hline Контроль & 32,1 & 83,3 & 27,1 & 90,0 & 28,2 & 63,3 & 35,8 & 93,3 \\
\hline Раксил & 7,5 & 26,7 & 15,0 & 46,7 & 17,5 & 58,3 & 23,3 & 66,7 \\
\hline ТБК $\mathrm{Na}_{2}$ ГК 0,3 & 5,4 & 21,7 & 14,6 & 56,7 & 14,2 & 56,7 & 20,8 & 65,0 \\
\hline ТБК $\mathrm{Na}_{2} Г К ~ 0,1$ & 11,3 & 41,7 & 18,3 & 65,0 & 13,8 & 73,3 & 28,3 & 80,0 \\
\hline
\end{tabular}


Таблица 3

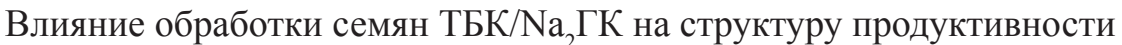
и урожайность мягкой яровой пшеницы и ярового ячменя

\begin{tabular}{|c|c|c|c|c|c|c|c|c|c|c|}
\hline \multirow{2}{*}{$\begin{array}{c}\text { Показатель } \\
\text { продуктив- } \\
\text { ности }\end{array}$} & \multicolumn{5}{|c|}{ Пшеница мягкая яровая } & \multicolumn{5}{|c|}{ Ячмень яровой } \\
\hline & $\begin{array}{l}\text { Кон- } \\
\text { троль }\end{array}$ & $\begin{array}{l}\text { Рак- } \\
\text { сил }\end{array}$ & $\begin{array}{c}\text { ТБК } \\
\mathrm{Na}_{2} \Gamma К 0,3\end{array}$ & $\begin{array}{c}\text { ТБК } \\
\mathrm{Na}_{2} \text { ГК } 0,1\end{array}$ & $\mathrm{HCP}_{05}$ & $\begin{array}{l}\text { Кон- } \\
\text { троль }\end{array}$ & $\begin{array}{l}\text { Рак- } \\
\text { сил }\end{array}$ & $\begin{array}{c}\text { ТБК } \\
\mathrm{Na}_{2} \Gamma \mathrm{K} 0,3\end{array}$ & $\begin{array}{c}\text { ТБК } \\
\mathrm{Na}_{2} \Gamma К 0,1\end{array}$ & $\mathrm{HCP}_{05}$ \\
\hline $\begin{array}{c}\text { Длина } \\
\text { колоса, см }\end{array}$ & 8,14 & 8,76 & 8,79 & 8,50 & 0,13 & 7,7 & 8,0 & 8,5 & 8,3 & 0,28 \\
\hline $\begin{array}{c}\text { Число } \\
\text { колосков } \\
\text { в главном } \\
\text { колосе, шт. }\end{array}$ & 13,11 & 13,54 & 13,68 & 13,26 & 0,23 & 10,6 & 11,1 & 11,5 & 10,6 & 0,27 \\
\hline $\begin{array}{c}\text { Число зерен } \\
\text { в главном } \\
\text { колосе, шт. } \\
\end{array}$ & 26,9 & 28,5 & 28,9 & 27,5 & 0,59 & 18,8 & 20,3 & 21,2 & 19,9 & 0,40 \\
\hline $\begin{array}{l}\text { Масса зерна } \\
\text { с } 1 \text { растения, Г }\end{array}$ & 1,06 & 1,27 & 1,37 & 1,16 & 0,08 & 1,21 & 1,47 & 1,61 & 1,29 & 0,10 \\
\hline $\begin{array}{c}\text { Масса } \\
1000 \text { зерен, г }\end{array}$ & 33,7 & 34,4 & 34,8 & 34,9 & 0,28 & 46,6 & 46,9 & 48,1 & 47,8 & 0,63 \\
\hline $\begin{array}{c}\text { Урожайность, } \\
\text { т/га }\end{array}$ & 2,45 & 2,61 & 2,65 & 2,59 & 0,06 & 2,51 & 2,58 & 2,70 & 2,65 & 0,05 \\
\hline
\end{tabular}

\section{Выводы}

1. Композиции ТБК с глицирризиновой кислотой и ее натриевой солью достоверно увеличивают проникновение ТБК во внутренний объем обработанного зерна, что способствует оздоровлению на примерах зерновок мягкой яровой пшеницы и ярового ячменя от семенной инфекции; снижают развитие и распространение обыкновенной корневой гнили на первых этапах органогенеза яровой пшеницы и ярового ячменя.

2. Обработка семян композициями ТБК с глицирризиновой кислотой и ее натриевой солью повышает основные показатели структуры продуктивности и урожайность яровой пшеницы и ярового ячменя. При снижении нормы расхода ТБК/ $\mathrm{Na}_{2} \Gamma \mathrm{K}$ в 3 раза урожайность зерна яровой пшеницы соответствует таковой эталонного протравителя, а ячменя - существенно превышает этот показатель.

Работа выполнена при финансовой поддержке РФФИ (проект № 15-29-05835).

\section{Список литературы}

1. Долженко В.И. Современные требования к формированию ассортимента фунгицидов и протравителей/ В.И. Долженко, Г.Ш. Котикова, Д.А. Орехов // Агро XXI. 1999. - C. 3-4.

2. Душкин А.В., Метелева Е.С., Толстикова Т.Г., Хвостов М.В., Долгих М.П., Толстиков Г.А. // Химия в интересах устойчивого развития. - 2010. - Т. 18, № 4. - С. 517-525.

3. Койшыбаев М. Протравливание семян зерновых культур в Казахстане / М. Койшыбаев //Защита и карантин растений - 2000. - № 1. - С. 14-16.

4. Новикова И.И. Полифункциональные биопрепараты для защиты растений от болезней/ И.И. Новикова // Защита и карантин растений. - 2005. - № 2. - С. 22-24.

5. Протравливание семенного материала: рекомендации /В.И. Долженко, Г.Ш. Котикова, С.Д. Здрожевская и др. М.-Санкт-Петербург, ООО «Изд-во Агрорус», 2003. - 61 с.

6. Санин С.С. Методические указания по проведению производственных демонстрационных испытаний средств и методов защиты зерновых культур от болезней / С.С. Санин, Н.П. Неклеса // Защита и карантин растений. - 2004. - С. 24.

7. Тепляков Б.И. Методика учёта корневой гнили требует усовершенствования // Защита и карантин растений. 2004. - № 7. - C. 32-33.

8. Deep P. Patel, Dr.Bharat G. Chaudhari. Application of Supramolecules in Drug Delivery // Journal of Current Pharmaceutical Research. - 2012. - Vol. 9. № 1. - P. 1-5.

9. Dushkin A.V., Tolstikova T.G., Khvostov M.V., Tolstikov G.A.// in book The Complex World of Polysacchraids, ed.by Dr. D.N. Karunaratn. - Publisher: InTech. - 2012. - P. 573-602.

10. Selyutina O.Yu, Polyakov N.E., Korneev D.V., Zaitsev B.N. // Drug Delivery. - 2016. - Vol. 23, № 3. - P. 848-855. 